\title{
Early outcomes of kidney transplantation from elderly donors after circulatory death (GEODAS study)
}

María José Pérez-Sáez ${ }^{1}$, Omar Lafuente Covarrubias², Domingo Hernández ${ }^{3}$, Francesc Moreso ${ }^{4}$, Edoardo Melilli, Javier Juega ${ }^{6}$, Erika de Sousa ${ }^{7}$, Paula López-Sánchez ${ }^{2}$, María Luisa Rodríguez-Ferrero ${ }^{8}$, Naroa Maruri-Kareaga ${ }^{9}$, María Dolores Navarro ${ }^{10}$, Rosalía Valero ${ }^{11}$, María Auxiliadora Mazuecos ${ }^{12}$, Francisco Llamas $^{13}$,

Paloma Martín-Moreno ${ }^{14}$, Antón Fernández-García ${ }^{15}$, Jordi Espi ${ }^{16}$, Carlos Jiménez ${ }^{17}$, Ana Ramos ${ }^{18}$, Eva Gavela ${ }^{19}$, Julio Pascual ${ }^{1 *+}$, Jose M. Portolés ${ }^{2^{*+}}$ (1) and on behalf of the GEODAS Group

\begin{abstract}
Background: Spain has dramatically increased the number of controlled circulatory death donors (CDCD). The initial selection criteria for considering CDCD for kidney transplantation (KT) have been expanded progressively, with practically no limits in donor age during the last years. We aimed to analyze the early clinical outcomes using expanded ( $>65$ years) CDCD in comparison with standard ones.

Methods: Observational multicenter study including 19 transplant centers in Spain. We performed a systematic inclusion in a central database of every KT from expanded CDCD at each participant unit from January-2012 to January-2017. Surgical procedures and immunosuppressive protocols were based on local practices. Data was analyzed in the central office using logistic and Cox regression or competitive-risk models for multivariate analysis. Median time of follow-up was 18.1 months.

Results: 561 KT were performed with kidneys from CDCD, 135 from donors older than 65 years. As expected, recipients from older CDCD were also older (65.8 (SD 8.8) vs 53.7 (SD 11.4) years; $p<0.001$ ) and with higher comorbidity. At 1 year, no differences were found amongst older and younger CDCD KT recipients in terms of serum creatinine (1.6 (SD 0.7) vs 1.5 (SD 0.8) $\mathrm{mg} / \mathrm{dl} ; p=0.29$ ). Non-death censored graft survival was inferior, but death-censored graft survival was not different ( 95.5 vs $98.2 \%$ respectively; $p=0.481$ ). They also presented a trend towards higher delayed graft function ( 55.4 vs $46.7 \% ; p=0.09$ ) but a similar rate of primary non-function (3.7 vs $3.1 \% ; p=0.71$ ), and acute rejection (3.0 vs 6.3\%; $p=0.135$ ). In the multivariate analysis, in short follow-up, donor age was not related with worse survival or poor kidney function (eGFR $<30 \mathrm{ml} / \mathrm{min}$ ).

(Continued on next page)
\end{abstract}

\footnotetext{
*Correspondence: julpascual@gmail.com; josem.portoles@salud.madrid.org

†Julio Pascual and Jose M. Portolés are Senior co-authorship.

${ }^{1}$ Nephrology Department and Kidney Transplantation Program, Hospital del

Mar, Parc de Salut Mar, Universitat Autónoma Barcelona and Universitat

Pompeu Fabra, Nephropaties Research Group Institute Mar for Medical

Research, Passeig Maritim 25-29, 08003 Barcelona, Spain

${ }^{2}$ Nephrology \& Transplant Department, University Hospital Puerta de Hierro,

Universidad Autónoma Madrid, Public Research Net RedlnRen ISCIII 016/009,

C/Manuel de Falla s/n, 28222 Majadahonda, Madrid, Spain

Full list of author information is available at the end of the article
}

(c) The Author(s). 2019 Open Access This article is distributed under the terms of the Creative Commons Attribution 4.0 International License (http://creativecommons.org/licenses/by/4.0/), which permits unrestricted use, distribution, and reproduction in any medium, provided you give appropriate credit to the original author(s) and the source, provide a link to the Creative Commons license, and indicate if changes were made. The Creative Commons Public Domain Dedication waiver (http://creativecommons.org/publicdomain/zero/1.0/) applies to the data made available in this article, unless otherwise stated. 
(Continued from previous page)

Conclusions: The use of kidneys from expanded CDCD is increasing for older and comorbid patients. Short-term graft outcomes are similar for expanded and standard CDCD, so they constitute a good-enough source of kidneys to improve the options of KT wait-listed patients.

Keywords: Kidney transplantation, Elderly donors, Donors after circulatory death, Clinical outcomes, Delayed graft function

\section{Background}

Kidney transplantation (KT) from donors after cardiac death (DCD) might imply poorer graft outcomes, as circulatory death constitutes an injury to the organs that may result in lower graft survival [1]. To minimize that, DCD are only considered for KT if they fit strict criteria, including younger donor age than donors after brain death (DBD). In the US, around $50 \%$ of expanded criteria donor (ECD)-DCD kidneys are discarded, compared to $30-40 \%$ of ECD-DBD [2]. However, a significant number of discarded ECD-DCD kidneys may be acceptable for KT [2]. In fact, as age of patients listed for $\mathrm{KT}$ is continuously rising [3, 4], DCD age criteria has also increased in recent years in many countries, especially in Europe [5-11], where policies are more open to expand donor pool criteria, in contrast to the US, where the potential poorer outcomes could lead to a higher discarded organ rate.

In Spain, improvements in organ procurement and assessment tools have allowed us to expand donor acceptance criteria [12]. Particularly, age limits have been expanding, so that age itself is not usually a significant limiting factor. In contrast, more than half of available kidneys from donors $\geq 65$ years old are discarded in the US [13], despite their argued benefits in terms of patient survival, both after brain death [14-16] and after circulatory death [17], comparing to remain on dialysis. However, the increase in donor age is associated with reduced graft function as well as limited recipient and graft survival [18]. Moreover, it has been recently postulated that the use of aged DCD could be detrimental in elderly recipients $[10,11]$.

In 2012, Spain developed a strategy to encourage the use of controlled DCD (cDCD) for transplantation, a modality less used in our environment because of the high rate of brain-death donation [19]. That resulted in a dramatic increase in CDCD transplantation, from 1.4\% of the total donors in 2012 to $18 \%$ in 2016 [20]. The same year, GEODAS working group was created with the purposes of: 1) collecting data regarding $\mathrm{KT}$ from cDCD; and 2) sharing protocols, outcomes analysis and experiences [21].

As donor age in this modality has also experienced a substantial change during the last years, we aimed to analyze the early results obtained with KT from elderly $\mathrm{CDCD}$ donors, both in terms of early clinical outcomes - primary non function (PNF) and delayed graft function (DGF) - as well as 1st year patient and graft survival, in order to reassure with the strategy of using these kidneys for aged recipients or change the policy if needed.

\section{Methods}

Observational and multi-center registry, including 19 transplant centers in Spain. Data from all cDCD (Maastricht type III) KT performed from January 2012 to January 2017 were collected and prospectively recorded by nephrologists at each center database following the same structure. For this analysis, a data manager central office merged anonymous databases in a single one. Informed consent for kidney transplantation and local electronic data management was obtained according to each center's Institutional Review Board policy, and a central research Ethics Committee of H.U. Puerta de Hierro approved the project. A pre-defined analysis after the first $500 \mathrm{cDCD}$ KT was performed in order to evaluate the early results obtained with kidneys from donors over 65 years, and to establish strategy changes if needed. This age cut-point was chosen based on the upper limit recommended by the 1st version of Spanish National Transplant Organization cDCD strategy guides in 2012 [19]. In Spain, old donors usually allocate into old recipients, but there are not any pre-established common strategy between centers, being the finally decision made by each center. Sample size was estimated for a 15\% difference in DGF incidence rate between groups.

Graft extraction was performed with or without antemortem vascular cannulation, depending on the center. The immunosuppressive regimen included induction with rabbit anti-thymocyte globulin (Thymoglobulin ${ }^{\oplus}$, Sanofi, France) or basiliximab (Simulect ${ }^{\oplus}$ Novartis, Swizerland), and maintenance with steroids as well as the combination tacrolimus-mycophenolate or tacrolimus-everolimus, tailored to patient immunological risk and according to center's local practice.

Local standardized serum creatinine (colorimetric) and glomerular filtration rate (GRF) estimated by ModifiedDiet Renal Disease-4 (MDRD-4) formula were recorded at month 1, 3, 6 and every 6 months thereafter. Clinical 
events such as acute rejection, graft loss or patient death were recorded as they occurred. Delayed graft function (DGF) was defined as the need of dialysis during the 1st week after KT.

\section{Statistics}

Data are shown as mean and standard deviation or percentages and event rates depending on variable nature. Continuous variables were compared using t-Student statistics or Wilcoxon's test if variables were not normally distributed. Categorical variables were compared with two-tailed Chi-square statistics. Significance was considered when $p<0.05$. Patient and graft survival was estimated by Kaplan-Meier curves (log-rank test). Three statistical models for survival were used to increase the robustness of the analysis: logistic regression, Cox regression and competing risk regression analyses.

Logistic regression was used to estimate Odds Ratio (OR) for 1st year cumulative mortality. Uni and multivariate Cox regression models were carried out to estimate hazard ratio (HR) for survival. Backward step multivariable regression was performed with principal variable (old vs. young donor), considering as possible confounders from donor those included in KDPI (ethnicity, cause of death, serum creatinine $>1.5 \mathrm{mg} / \mathrm{dl}$, diabetes mellitus, hypertension, etc.). We also included other potential confounders as recipient age, sex and comorbidity, cold ischemia time (CIT), human leukocyte antigen (HLA) mismatches, prior dialysis modality, prior $\mathrm{KT}$, time on dialysis prior to transplant as well as other usual risk variables such as serum creatinine or induction treatment. Variables with $p$ value $<0.1$ in the univariate analysis were included in the multivariable backward modeling process, besides other variables that were clinically relevant for the outcome. We also used competitive-risk models for graft and patient survival, considering graft loss, death and loss to follow-up as competitive events. Results are shown as sub-Hazard Ratio (sHR).

On the other hand, we tested multivariate models for the impact of donor age group on early clinical outcomes: primary-non-function (PNF, defined as grafts that never functioned), DGF, poor kidney function at 12 months (defined as eGFR $<30 \mathrm{~mL} / \mathrm{min}$ ). Patients with PNF were excluded for further analyses of other outcomes.

Analysis was performed using Stata v14 (StataCorp 2015, Stata Statistical Software, College Station, TX).

\section{Results}

$561 \mathrm{KT}$ recipients from $\mathrm{CDCD}$ were included in the study. Of them, 135 received a KT from a $\mathrm{cDCD}$ donor $>65$ years. Compared to patients that received a KT from a younger donor, patients that received a $\mathrm{KT}$ from $\mathrm{CDCD}>$ 65 years were older $(65.8$ (8.8) years vs 53.7 (11.4) years, $p<0.001)$, more frequently females, diabetics $(51.4 \%$ vs $26.1 \%, \mathrm{p}<0.001)$ and with higher percentage of previous cardiovascular events $(20.7 \%$ vs $7.8 \%, \mathrm{p}<0.001)$. Donor cause of death was more frequently a stroke. They were also better HLA matched and received less frequently thymoglobulin as induction therapy (Table 1).

Regarding early clinical events, the group that received a KT from an older CDCD experienced a trend towards higher rate of DGF, though the difference was not statistically significant $(55.4 \%$ vs $46.7 \%, p=0.09)$. Neither we found any difference in PNF or acute rejection rates (Table 2). When analyzing other potential risk factors for PNF and DGF through logistic regression models, CIT longer than $17 \mathrm{~h}$ was found to be a risk factor for PNF (OR 3.25 [1.02-10.33; $p=0.046]$ ), while dialysis vintage longer than 24 months prior to $\mathrm{KT}$ conditioned DGF (OR 3.44 [2.39-4.94; $p<0.001$, Table 3).

In terms of graft function, recipients from older donors showed lower eGFR at 1 year, but not statistically different serum creatinine $(1.60$ vs $1.51 \mathrm{mg} / \mathrm{dl} ; p=0.29$, Table 2). In the multivariate analysis, the risk for poor renal function (1st year eGFR $<30 \mathrm{ml} / \mathrm{min}$ ) associated with DGF (4.12 [2.07-8.22]; $\mathrm{p}<0.001)$ but not with donor age (Table 3).

On the other hand, cumulative mortality during 1st year was higher for recipients of older cDCD grafts ( $1.9 \%$ vs $6.9 \% ; p=0.004$, Table 2$)$. Logistic regression model adjusted by recipient age and comorbidities showed that recipient age was the only risk factor related to patient death, conferring a $11 \%$ excess risk for mortality per each recipient's year (OR 1.11 [1.04-1.19]; $p=0.002$, Table 3).

Survival analyses (estimated by KM method) showed a lower 1st-year-graft survival among those kidneys from cDCD donors $>65$ years $(87.6 \%$ vs $96.2 \% ; p=0.02)$. However, death-censored graft survival was similar in both groups $(95.5 \%$ vs $98.25 ; p=0.481$ ) (Fig. 1). We performed Cox regression and competing risk multivariate analyses in order to analyze donor age impact on graft survival. Adjusted-models did not show that donor age itself and isolated was associated with graft survival but eGFR $<30 \mathrm{ml} / \mathrm{min}$ at 1-year increased the risk eight -fold (sHR 8.34 [2.82-24.65; p < 0.001, Table 4).

On the other hand, 1st-year patient survival was also poorer $(91.8 \%$ vs $97.9 \% ; p=0.01)$. Nine patients from the group of older donors died with functioning graft during the first year after transplantation (mostly in the first 6 months after transplantation) due to cardiovascular events $(n=4)$, sudden death of uncertain origin $(n=1)$, cancer $(n=1)$, sepsis $(n=1)$, pulmonary embolism $(n=1)$, and unknown cause $(n=1)$. Again, the multivariate analysis revealed that only recipient age was as risk factor for patient survival, increasing the risk around 10\% per each recipient's year of age, both with Cox and competing risk analyses (Table 4). 
Table 1 Baseline characteristics among kidney transplant recipients from donors $>65$ years and $\leq 65$ years

\begin{tabular}{|c|c|c|c|}
\hline & $\begin{array}{l}\text { Donor } \leq 65 \text { years } \\
(n=426)\end{array}$ & $\begin{array}{l}\text { Donor }>65 \text { years } \\
(n=135)\end{array}$ & $p$-value \\
\hline \multicolumn{4}{|l|}{ Recipient characteristics } \\
\hline Age (years, mean (SD)) & $53.7(11.4)$ & $65.8(8.8)$ & $<0.001$ \\
\hline Age > 65 years $(\%)$ & 14.6 & 61.3 & $<0.001$ \\
\hline Female Gender (\%) & 30.1 & 35.6 & 0.23 \\
\hline Black Race (\%) & 1.4 & 0.7 & 0.5 \\
\hline Diabetes mellitus (\%) & 26.1 & 51.4 & $<0.001$ \\
\hline Previous cardiovascular event ${ }^{\mathrm{a}}(\%)$ & 7.8 & 20.7 & $<0.001$ \\
\hline \multicolumn{4}{|l|}{ Cause of end-stage renal disease (\%) } \\
\hline Hypertensive nephropathy & 12.4 & 11.9 & \\
\hline Diabetic nephropathy & 11.3 & 22.2 & \\
\hline Glomerulonephritis & 19.0 & 12.6 & \\
\hline Interstitial & 11.0 & 11.9 & 0.03 \\
\hline Polycystic & 15.3 & 11.1 & \\
\hline Others & 6.7 & 5.9 & \\
\hline Unknown & 19.7 & 23.7 & \\
\hline \multicolumn{4}{|l|}{ Previous renal replacement therapy (\%) } \\
\hline Hemodialysis & 73.1 & 83.0 & \\
\hline Peritoneal Dialysis & 21.0 & 14.8 & 0.05 \\
\hline Preemptive kidney transplant & 5.9 & 2.2 & \\
\hline Dialysis vintage (years, median [IQR]) & $1.1[2.0-3.6]$ & $1.3[2.6-4.0]$ & 0.08 \\
\hline Patients with previous kidney transplant (\%) & 8.4 & 7.4 & 0.7 \\
\hline \multicolumn{4}{|l|}{ Donor characteristics } \\
\hline Age (years, mean (SD)) & $52.7(9.1)$ & $72.0(4.9)$ & $<0.001$ \\
\hline Female Gender (\%) & 26.3 & 45.9 & $<0.001$ \\
\hline Expanded criteria donors (\%) & 29.3 & 100 & $<0.001$ \\
\hline Stroke as Cause of death (\%) & 49.2 & 67.8 & $<0.001$ \\
\hline \multicolumn{4}{|l|}{ Transplant characteristics } \\
\hline Number of HLA mismatches (median (IQR)) & $4[3-5]$ & $4[3-5]$ & 0.003 \\
\hline Cold ischemia time (hours, median (IQR)) & $11[7-18]$ & $9.5[7-16.5]$ & 0.326 \\
\hline Warm ischemia time (min, median (IQR)) & $23.5[15-36.5]$ & 26 [16-35] & 0.901 \\
\hline Induction treatment (Thymoglobulin, \%) & 70.7 & 57 & 0.003 \\
\hline Maintenance (Tacrolimus+MPA + steroids, \%) & 82.9 & 80.7 & 0.57 \\
\hline Time of follow-up (years, median [IQR]) & $1.6[0.9-2.6]$ & $1.1[0.7-1.8]$ & $<0.001$ \\
\hline
\end{tabular}

SD standard deviation, MPA mycophenolic acid, IQR interquartile range

${ }^{a}$ Acute myocardial infarction, stroke or peripheral vascular disease (amputation)

Table 2 Patient and transplant outcomes among kidney transplant recipients from donors $>65$ years and $\leq 65$ years

\begin{tabular}{llll}
\hline & $\begin{array}{l}\text { Donor } \leq 65 \text { years } \\
(n=426)\end{array}$ & $\begin{array}{l}\text { Donor }>65 \text { years } \\
(n=135)\end{array}$ & $p$-value \\
\hline Early patient mortality (at first year, \%) & 1.9 & 6.9 & 3.7 \\
Primary non-function (\%) & 3.1 & 55.4 & 0.004 \\
Delayed graft function (\%) & 46.7 & 3.0 & 0.71 \\
Acute rejection (\%) & 6.3 & $1.60(0.7)$ & 0.135 \\
Creatinine at 12 month (mg/dl, mean (SD)) & $1.51(0.8)$ & $49.2(20.0)$ & 0.29 \\
eGFR at 12 month (ml/min, mean (SD)) & $57.9(24.7)$ & & $<0.001$ \\
\hline
\end{tabular}


Table 3 Risk factors for relevant patient and allograft early outcomes estimated with multivariate logistic regression analysis

\begin{tabular}{llll}
\hline & OR & $95 \% \mathrm{Cl}$ & $p$-value \\
\hline Primary non-function & & & \\
Donor age $>65$ years (vs $\leq 65$ years) & 2.50 & {$[0.77-8.09]$} & 0.128 \\
Cold ischemia time $>17 \mathrm{~h}$ (vs shorter) & 3.25 & {$[1.02-10.33]$} & 0.046 \\
Delayed graft function & & & \\
$\quad$ Donor age $>65$ years (vs $\leq 65$ years) & 1.33 & {$[0.87-2.03]$} & 0.19 \\
Dialysis vintage $>24$ months (vs shorter) & 3.44 & {$[2.39-4.94]$} & $<0.001$ \\
eGFR< $30 \mathrm{ml} /$ min at month 12 & & & \\
Donor age $>65$ years (vs $\leq 65$ years) & 1.15 & {$[0.60-2.20]$} & 0.427 \\
Delayed graft function (vs immediate) & 4.12 & {$[2.07-8.22]$} & $<0.001$ \\
Early patient mortality (first year) & & & \\
Donor age $>65$ year (vs $\leq 65$ years) & 1.37 & {$[0.46-4.10]$} & 0.578 \\
Recipient age (per year) & 1.11 & {$[1.04-1.19]$} & 0.002 \\
\hline OR
\end{tabular}

Finally, we aimed to investigate which old donors might carry a higher risk for the recipients, considering early clinical outcomes. By adding classical donor cardiovascular risk factors (serum creatinine $>1.5 \mathrm{mg} / \mathrm{dl}$, diabetes mellitus and cardiovascular as the cause of death), we found that older donors with one or two of those previous risk factors associated with significant higher DGF rate (Table 5). Similar analyses for PNF, poor kidney function (1st year eGFR $<30 \mathrm{ml} / \mathrm{min}$ ) and 1 st year mortality were not significant (data not shown).

\section{Discussion}

In this study, we present early clinical outcomes using $\mathrm{KT}$ from $\mathrm{cDCD}$ older than 65 years. We found higher 1st year mortality among KT patients receiving a kidney from an elderly donor, but it seems to be related to recipient age. Donor age itself and isolated did not have any impact on patient neither graft survival at short term, although it was associated with poorer graft function in terms of eGFR.

As ECD-DCD donors may constitute more than 40\% of the total DCD donor pool in some centers [11], efforts are targeted now to analyze outcomes using kidneys that come from those suboptimal donors. Some reports have analyzed outcomes using ECD-DCD donors in the US [1, 22, 23], Europe [7-11] and Japan [24]. Overall, results from ECD-DCD donors are poorer than those obtained with standard-DCD donors, though not inferior to ECD-DBD donors [1, 7, 9, 22, 24]. However, these studies included KT recipients from classical ECD defined by Organ Procurement Transplant Network (OPTN, donors older than 60 years-old, or between 50 and 60 years-old with two of the following risk factors: cardiovascular death, serum creatinine $>1.5 \mathrm{mg} / \mathrm{dl}$ or hypertension) but few studies have analyzed the results with very elderly donors, i.e., older than 65 years-old [10].

Normally, studies have not been focused on patient survival using expanded DCD donors, though we can find a reported one-year-patient survival ranged from 85 to $91 \%$ among recipients who received kidneys from ECD-DCD donors [7, 10, 23]. Two studies also compared the mortality between those who underwent KT from an ECD-DCD donor and those who remained waitlisted on dialysis. They found that among older recipients ( $>65$ years), there was no benefit in terms of survival using kidneys from old DCD donors ( $>65$ years) $[10,11]$, and younger recipients might have the potential benefit of the expansion in DCD donor criteria acceptance [11]. In a recent observational study in patients

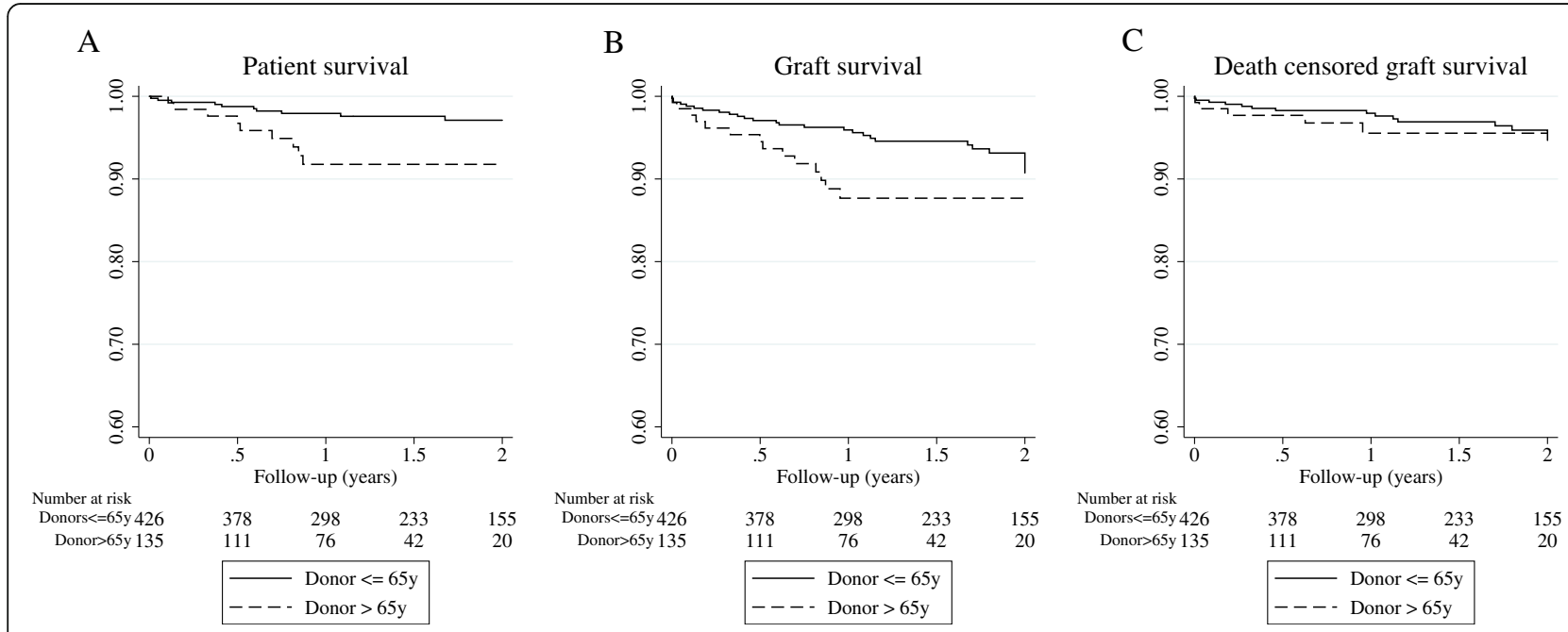

Fig. 1 Kaplan-Meier survival curves between kidney transplant recipients from donors $>65$ years and $\leq 65$ years. a Patient survival; b Graft survival; c Death-censored graft survival 
Table 4 Risk factors for relevant patient and allograft early outcomes estimated with Cox regression analysis (HR) and competing risk analysis (sHR)

\begin{tabular}{|c|c|c|c|c|c|c|c|}
\hline & Risk factor & $H R$ & $95 \% \mathrm{Cl}$ & $p$-value & sHR & $95 \% \mathrm{Cl}$ & $p$-value \\
\hline \multicolumn{8}{|l|}{ Patient survival } \\
\hline Model 1 (raw) & Donor age $>65 y$ (vs $\leq 65$ years) & 2.94 & {$[1.22-7.11]$} & 0.016 & 3.17 & {$[1.38-7.27]$} & 0.015 \\
\hline \multirow[t]{2}{*}{ Model 2 (adjusted by recipient age) } & Donor age $>65 y$ (vs $\leq 65$ years) & 1.17 & {$[0.44-3.08]$} & 0.751 & 1.26 & {$[0.48-3.34]$} & 0.636 \\
\hline & Recipient age & 1.10 & {$[1.04-1.16]$} & 0.001 & 1.1 & {$[1.05-1.16]$} & $<0.001$ \\
\hline \multirow[t]{3}{*}{ Model 3 (adjusted by recipient age + previous CV event) } & Donor age $>65 y$ (vs $\leq 65$ years) & 1.06 & {$[0.40-2.82]$} & 0.900 & 1.06 & {$[0.36-3.12]$} & 0.910 \\
\hline & Recipient age & 1.10 & {$[1.04-1.16]$} & 0.001 & 1.09 & {$[1.04-1.15]$} & $<0.001$ \\
\hline & Previous CV event & 2.02 & {$[0.76-5.36]$} & 0.158 & 2.00 & {$[0.73-5.47]$} & 0.178 \\
\hline \multicolumn{8}{|l|}{ Death-censored graft survival } \\
\hline Model 1 (raw) & Donor age $>65 y$ (vs $\leq 65$ years) & 1.30 & {$[0.47-3.60]$} & 0.620 & 1.28 & {$[0.47-3.47]$} & 0.631 \\
\hline \multirow[t]{2}{*}{ Model 2 (adjusted by recipient age) } & Donor age $>65 y$ (vs $\leq 65$ years) & 1.17 & {$[0.44-3.08]$} & 0.751 & 1.00 & {$[0.30-3.38]$} & 0.997 \\
\hline & Recipient age & 1.10 & {$[1.04-1.16]$} & 0.001 & 1.02 & {$[0.97-1.07]$} & 0.425 \\
\hline \multirow[t]{2}{*}{ Model 3 (adjusted by eGFR<30 ml/min at first month) } & Donor age $>65 y$ (vs $\leq 65$ years) & 0.66 & $0.15-3.01$ & 0.595 & 0.58 & {$[0.12-2.74]$} & 0.487 \\
\hline & eGFR $<30 \mathrm{ml} / \mathrm{min}$ at first month & 8.70 & $2.99-25.25$ & $<0.001$ & 8.34 & $2.82-24.65$ & $<0.001$ \\
\hline
\end{tabular}

$H R$ hazard ratio, sHR sub-hazard ratio, $\mathrm{Cl}$ confidence interval, eGFR estimated glomerular filtration rate, $\mathrm{CV}$ cardiovascular

older than 65 years old receiving an old kidney from DCD donors over 65, Peter-Sengers et al. showed a $15 \%$ higher mortality than we found among our recipients. Although we have included recipients younger than 65 years old, our cohort included recipients of a special high-risk profile, with a mean age near 66 years, high prevalence of diabetes $(>50 \%)$ and previous cardiovascular events $(>20 \%)$. When we analyzed the risk factors implicated in early patient survival, we confirmed that only patient age was involved in patient prognosis without any influence of donor age or donor comorbidity. These findings highlight the importance of a carefully selection of the recipient, in order to avoid early patient mortality.

In terms of graft survival, kidney grafts from ECDDCD donors have shown inferior survival than those from standard DCD donors [1, 24], though similar to ECD-DBD ones [7, 22]. One-year-graft survival has been reported from 74 to $90 \%$ [7, 9, 23, 24], similar to ours, despite our donors were almost 5 years older than those from the study by Peter-Sengers et al. which reported the oldest ones so far [10]. In fact, we found no

Table 5 Risk factors for relevant renal allograft outcomes estimated with logistic regression analysis

\begin{tabular}{|c|c|c|c|}
\hline & OR & $95 \% \mathrm{Cl}$ & $p$-value \\
\hline \multicolumn{4}{|l|}{ Delayed graft function } \\
\hline Donor age $>65$ years +0 risk factor & 1.32 & $0.79-2.22$ & 0.30 \\
\hline Donor age $>65$ years +1 risk factor & 1.79 & $1.05-3.05$ & 0.03 \\
\hline Donor age $>65$ years +2 risk factors & 3.84 & $1.91-7.72$ & $<0.001$ \\
\hline \multicolumn{4}{|c|}{$\begin{array}{l}\text { Donor risk factors are defined as creatinine }>1.5 \mathrm{mg} / \mathrm{dl} \text {, cardiovascular death } \\
\text { and hypertension. Similar analyses for Primary non function, estimated } \\
\text { glomerular filtration rate }<30 \mathrm{ml} / \mathrm{min} \text { at } 12 \text { months and early patient mortality } \\
\text { were not significant }\end{array}$} \\
\hline
\end{tabular}

differences in 1st year death-censored-graft survival regardless donor age, highlighting that differences observed in non-censored graft survival are related to a higher rate of patient mortality during the 1st year within recipients who received a kidney from an older donor.

Disparities have been found in other outcomes such as DGF or PNF. While the US Registry found no differences in terms of among ECD-DCD donors and nonECD-DCD donors, the UK cohort found a higher rate of both PNF and DGF between older donors but comparing to donors younger than 40 years [7]. However, an update of the UK Registry showed similar rates of PNF and similar 5-year graft survival between ECDDCD and brain-dead ECD KT [8]. The study from the Netherlands found a high-rate of both PNF $(12.7 \%)$ and DGF $(74.1 \%)$ in recipients $>65 y$ who received organs from donors $>65$ y [10]. Our PNF rate was similar between the groups and below $4 \%$ and the only factor that increased the risk was a prolonged cold ischemia time, consistently with other authors' findings [7]. In our study, the incidence of DGF was high in both groups, with a clear tendency of higher rate among recipients from older donors. The multivariate analysis showed that donor age itself was not associated with higher rate of DGF, but if we considered high-risk donor profile (older plus other comorbidities) the risk is increased by three-fold.

Poorer kidney function has also been shown in kidneys from ECD-DCD donors [7, 9]. In fact, two-thirds of old recipients from DCD donors over 65 y presented with eGFR $<30 \mathrm{ml} / \mathrm{min}$ at 1 st year [10]. We did not find any statistical difference in terms of serum creatinine at 1st year after transplantation although kidney function was poorer in recipients from elderly $\mathrm{CDCD}$. 
Our study is limited by the sample size and the relative short-term follow-up. However, we aimed to analyze 1st year results using elderly $\mathrm{cDCD}$ in our media, to know results and implement the proper strategy changes if needed. In fact, this is the first study that analyzes outcomes in an important number of elderly cDCD (mean age 72 years) allocated to a high-risk recipient cohort. We found a higher mortality compared to recipients who received organs from younger donors. However, in the multivariate model the recipient age accounted for all the risk and the weight of the donor age over the death risk disappeared. Three different multivariate statistical models showed these results, which reflects their consistency. On the other hand, short-term graft survival was similar and donor age itself did not have any impact in patient or graft outcomes.

\section{Conclusions}

Our results pointed at similar patient and KT short-term outcomes regardless of donor age, which may suggest better results than those previously reported. If these findings were confirmed in long-term studies, they might generate changes in acceptance and allocation of these grafts for KT. In fact, when we added comorbidity factors other than donors' age, some outcomes as DGF seem to be affected. Careful pre-transplant evaluation should be performed in these extremely high-risk group in order to improve outcomes, but kidneys from old cDCD should not be discarded systematically.

\section{Abbreviations \\ CDCD: Controlled donor after circulatory dead; CIT: Cold ischemia time; DBD: Donor after brain death; DCD: Donor after circulatory death; DGF: Delayed graft function; ECD: Expanded criteria donor; eGFR: Estimated glomerular filtration rate; GEODAS (from the words in Spanish): Grupo Español de Trasplante renal con programas de Donante en Asistolia tipo 3 (Spanish Group with cDCD KidneyTransplant Programs); HLA: Human leucocyte antibody; KT: Kidney transplant; MDRD: Modified-diet renal disease; PNF: Primary non-function}

\section{Acknowledgements \\ The GEODAS Group comprises the following authors: José M. Portolés, Omar Lafuente Covarrubias, Paula López-Sánchez, Beatriz Sánchez-Sobrino (H.U. Puerta de Hierro, Madrid); María José Pérez-Sáez, Julio Pascual Santos, Ana Zapatero (H. del Mar, Barcelona); Domingo Hernández-Marrero (H.U. Carlos Haya, Málaga); Francesc Moreso (H. Vall d'Hebron, Barcelona); Edoardo Melilli, Anna Manonelles (H. Bellvitge, Hospitalet, Barcelona); Javier Juega, Ricardo Lauzurica (H. Germans Trias y Pujol, Badalona); Erika de Souza, Fritz Diekmann (H. Clinic, Barcelona); María Luisa Rodríguez-Ferrero (H.U. Gregorio Marañón (Madrid); Naroa Maruri-Kareaga, Sofia Zárraga (H. de Cruces, Bilbao); María Dolores Navarro, Alberto Rodríguez-Benot (H U. Reina Sofía, Córdoba); Rosalía Valero, Juan Carlos Ruiz (H. Marqués de Valdecilla, Santander); María Auxilia- dora Mazuecos (H Puerta del Mar, Cádiz); Francisco Llamas (C.H.U. General de Albacete); Paloma Martín-Moreno (Clínica Universitaria de Navarra); Ángel Alonso, Antón Fernández-García (C.H.U., A Coruña); Jordi Espí, Isabel Beneyto (H.U. La Fe, Valencia); Carlos Jiménez, María López-Oliva (H.U. La Paz, Madrid); Ana Ramos (Fundación Jiménez Díaz, Madrid): Eva Gavela, Asunción Sancho- Calabuig (H Dr Peset; Valencia)}

\section{Authors' contributions}

MJPS contributed to data collection, conceptualization of the idea, study design, statistical analysis and drafted the paper. OLC contributed to data collection and drafted the paper. PLS contributed to the study design and the statistical analysis. JMP contributed to conceptualization of the idea, study design, statistical analysis and drafted the paper. JP contributed to conceptualization of the idea, study design and drafted the paper. JMP and JP supervised the study. The rest of the authors (DH, FM, EM, JJ, EdS, MLRF, NMK, MDN, RV, MAM, FL, PMM, AFG, JE, CJ, AR, EG) contributed to data collection and the final revision of the manuscript. All authors read and approved the final manuscript.

\section{Funding}

This project was co-founded by Public Research Net REDINREN ISCIII 16/009/ 009, Renal Foundation FRIAT \& Research Institute Segovia Arana-HU Puerta de Hierro. OLC, PLS and JMP belong to the latter institution (HU Puerta de Hierro). Funding was used for human resources: data manager and statistician support.

\section{Availability of data and materials}

The database and the analysis are safeguarded in the central servers of a public health institution (Hospital Puerta de Hierro). Any access to the original database should be properly requested to the corresponding author and approved by Ethics Scientific Committee.

Ethics approval and consent to participate

Data from all KT were collected and prospectively recorded by nephrologists at each center database. A data manager central office merged anonymous databases auditing and debugging the data. Informed consent for kidney transplantation and local electronic data management was obtained according to each center's Institutional Review Board policy. A central research Ethics Committee of H.U. Puerta de Hierro approved the project without the need of additional consents.

\section{Consent for publication}

Not applicable. Data come from an anonymized database for the registry and the follow-up of kidney transplantation (not containing data from any individual person).

\section{Competing interests}

The authors declare that they have no competing interests.

\section{Author details}

${ }^{1}$ Nephrology Department and Kidney Transplantation Program, Hospital del Mar, Parc de Salut Mar, Universitat Autónoma Barcelona and Universitat Pompeu Fabra, Nephropaties Research Group Institute Mar for Medical Research, Passeig Maritim 25-29, 08003 Barcelona, Spain. ${ }^{2}$ Nephrology \& Transplant Department, University Hospital Puerta de Hierro, Universidad Autónoma Madrid, Public Research Net RedInRen ISCIII 016/009, C/Manuel de Falla s/n, 28222 Majadahonda, Madrid, Spain. ${ }^{3}$ H.U. Carlos Haya, Malaga, Spain. ${ }^{4} \mathrm{H}$. Vall d'Hebron, Barcelona, Spain. ${ }^{5} \mathrm{H}$. Bellvitge, Barcelona, Spain. ${ }^{6} \mathrm{H}$. German Trias y Pujol, Barcelona, Spain. ${ }^{7} \mathrm{H}$. Clinic de Barcelona, Barcelona, Spain. ${ }^{8}$ HGU Gregorio Marañón, Madrid, Spain. ${ }^{9}$ H.U. Cruces, Bilbao, Spain. ${ }^{10}$ H.U. Reina Sofia, Córdoba, Spain. ${ }^{11}$ H.U. Marqués de Valdecilla, Santander, Spain. ${ }^{12}$ H.U. Puerta del Mar, Cádiz, Spain. ${ }^{13}$ H.U. de Albacete, Albacete, Spain.

${ }^{14}$ C.U de Navarra, Pamplona, Spain. ${ }^{15}$ C.H.U de A Coruña, A Coruña, Spain. ${ }^{16}$ H.U. La Fe, Valencia, Spain. ${ }^{17}$ H.U. de la Paz, Madrid, Spain. ${ }^{18} \mathrm{~F}$. Jiménez Díaz, Madrid, Spain. ${ }^{19}$ H.U. Dr Peset, Valencia, Spain.

Received: 8 November 2018 Accepted: 6 June 2019 Published online: 26 June 2019

\section{References}

1. Locke J, Segev D, Warren D, Dominici F, Simpkins C, Montgomery R. Outcomes of kidneys from donors after cardiac death: implications for allocation and preservation. Am J Transplant. 2007;7:1797-807.

2. Singh SK, Kim SJ. Epidemiology of kidney discard from expanded criteria donors undergoing donation after circulatory death. Clin J Am Soc Nephrol. 2016;11(2):317-23

3. Catalan Renal Registry. Statistical report 2014. Barcelona, Spain: Catalan Transplant Organization, Health Department, 2016. Available at: http:// trasplantaments.gencat.cat/web/.content/minisite/trasplantament/registres_ activitat/registre_de_malalts_renals/arxius/Informe-estadistic-RMRC-2017.pdf 
4. 2016 USRDS Annual Data Report. Volume 2- ESRD in the United States. Chapter 1: Incidence, Prevalence, Patient Characteristics, and Treatment Modalities. Available at: https://www.usrds.org/2016/download/v2_c01_IncPrev_16.pdf

5. Balance de Actividad en Donación y Trasplante 2015. Available at: http:// www.ont.es/Documents/Balance_Actividad_2015.pdf

6. Eurotransplant International Foundation. Annual Report 2015. Available at: https://www.eurotransplant.org/cms/mediaobject.php?file=AR_ET_20153.pdf

7. Summers DM, Johnson RJ, Hudson A, et al. Effect of donor age and cold storage time on outcome in recipients of kidneys donated after circulatory death in the UK: a cohort study. Lancet. 2013;381:727-34.

8. Summers DM, Watson CJE, Pettigrew GJ, et al. Kidney donation after circulatory death (DCD): state of the art. Kidney Int. 2015;88:241-9.

9. Nagaraja P, Roberts GW, Stephens M, et al. Impact of expanded criteria variables on outcomes ok kidney transplantation from donors after cardiac death. Transplantation. 2015:99:299-31.

10. Peters-Sengers $\mathrm{H}$, Berger SP, Heemskerk MB, et al. Stretching the limits of renal transplantation in elderly recipients of grafts from elderly deceased donors. J Am Soc Nephrol. 2017;28(2):621-31.

11. Mirshekar-Syahkal B, Summers D, Bradbury LL, et al. Local expansion of donation after circulatory death kidney transplant activity improves waitlisted outcomes and addresses inequities of access to transplantation. Am J Transplant. 2017:17(2):390-400.

12. Chang GJ, Mahanty HD, Ascher NL, Roberts JP. Expanding the donor pool: can the Spanish model work in the United States? Am J Transplant. 2003; 3(10):1259-63.

13. Hart A, Smith JM, Skeans MA, et al. Kidney. Am J Transplant. 2016;16(Suppl 2):11-46.

14. Jay C, Washburn K, Dean P, et al. Survival benefit in older patients associated with earlier transplant with high KDPI kidneys. Transplantation. 2017;101(4):867-72.

15. Lloveras J, Arcos E, Comas J, Crespo M, Pascual J. A paired survival analysis comparing hemodialysis and kidney transplantation from deceased elderly donors older than 65 years. Transplantation. 2015;99:991-6.

16. Pérez-Sáez MJ, Arcos E, Comas J, et al. Survival benefit from kidney transplantation using kidneys from deceased donors aged $\geq 75$ years: a time-dependent analysis. Am J Transplant. 2016;16(9):2724-33.

17. Luo X, Missie A, Chow E, Segev D. Survival benefit of kidney transplantation with expanded criteria kidney from donors after circulatory death. Am J Transplant. 2015;15(S3):1-1 Abstract no. 291.

18. Pérez-Sáez MJ, Montero N, Redondo-Pachón D, et al. Strategies for an expanded use of kidneys from elderly donors. Transplantation. 2017;101(4): 727-45.

19. Donación en Asistolia en España: Situación actual y Recomendaciones Documento de Consenso 2012. Available at: http://www.ont.es/infesp/ DocumentosDeConsenso/DONACIÓN\%20EN\%20ASISTOLIA\%20EN\%20 ESPAÑA.\%20SITUACIÓN\%20ACTUAL\%20Y\%20RECOMENDACIONES.pdf.

20. Informe ONT 2016 .Available at: http://www.ont.es/infesp/Memorias/ Memoria\%20Trasplante\%20Renal.pdf

21. Portolés Pérez J, Lafuente O, Sánchez Sobrino B, et al. Kidney transplantation with organs from donors after circulatory death type 3 : a prospective multicentric Spanish study (GEODAS 3). Transplant Proc. 2015; 47:27-9.

22. Doshi MD, Hunsicker LG. Short- and long-term outcomes with the use of kidneys and livers donated after cardiac death. Am J Transplant. 2007;7:122-9.

23. Singh SK, Kim SJ. Does expanded criteria donor status modify the outcomes of kidney transplantation from donors after cardiac death? Am J Transplant. 2013;13(2):329-36.

24. Teraoka S, Nomoto K, Kikuchi K, et al. Outcomes of kidney transplants from non-heart-beating deceased donors as reported to the Japan organ transplant network from April 1995-December 2003: a multi-center report. Clin Transpl. 2004:91-102.

\section{Publisher's Note}

Springer Nature remains neutral with regard to jurisdictional claims in published maps and institutional affiliations.

\section{Ready to submit your research? Choose BMC and benefit from:}

- fast, convenient online submission

- thorough peer review by experienced researchers in your field

- rapid publication on acceptance

- support for research data, including large and complex data types

- gold Open Access which fosters wider collaboration and increased citations

- maximum visibility for your research: over $100 \mathrm{M}$ website views per year

At BMC, research is always in progress.

Learn more biomedcentral.com/submissions 